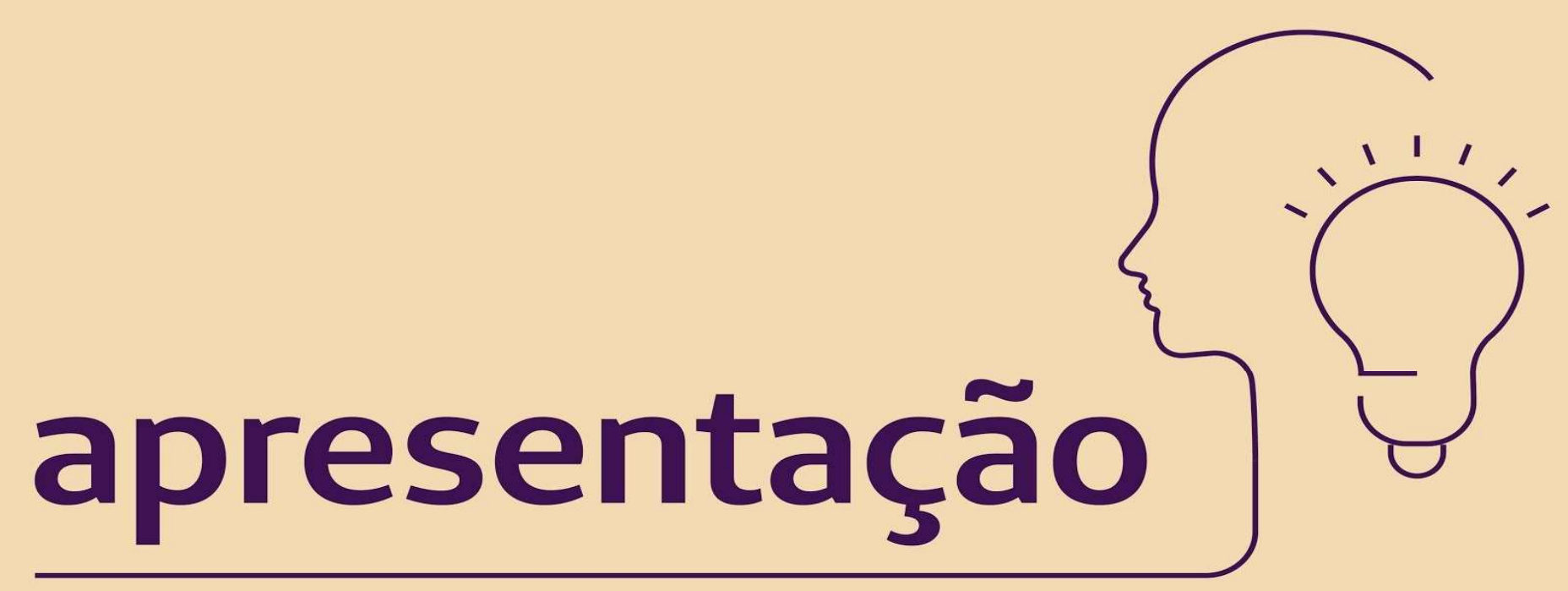

\title{
Democratizando o acesso ao conhecimento
}

O avanço da pandemia da COVID-19 alterou a rotina de milhões de pessoas em todo o globo. A fim de contribuir para o desenvolvimento científico, cultural e intelectual, especialmente durante um período tão desafiador como o atual, a Biblioteca Digital da Faculdade Unimed está com acesso livre e gratuito para toda a comunidade, por tempo indeterminado.

São mais de 1.000 títulos disponíveis nas áreas de Saúde, Gestão, Educação e Cooperativismo, entre livros, artigos, periódicos, teses e dissertações. Segundo a bibliotecária Fernanda Costa, responsável pelo projeto, esse número tem aumentado, com a inclusão de uma média de 30 materiais por dia.

"Como a produção de conhecimento não se esgota é feito um trabalho contínuo de adição de novos títulos para que a comunidade tenha acesso ao que há de mais recente no desenvolvimento científico. Nosso foco é conteúdo dos últimos cinco anos, selecionados com base na ementa dos nossos cursos de graduação e pós", completa.

Desde a sua criação em janeiro deste ano, foram contabilizados 1.335 acessos únicos, com pico de 533 visualizações apenas em maio. Comparando-se com o primeiro mês do seu funcionamento, o aumento foi de quase $500 \%$.

\section{Acervo diversificado}

No acervo, é possível encontrar materiais com diferentes temáticas como Políticas de Saúde no Brasil, Bioética e Ética na Gestão, Arquitetura Hospitalar, Cultura e Sociedade nas Organizações, História e Doutrina Cooperativista, entre outros. 
"A seleção tem como objetivo garantir a qualidade e confiabilidade de todas as obras, sendo totalmente de acordo com a lei de direitos autorais e adequadas paras as diferentes necessidades e níveis acadêmicos", esclarece Fernanda Costa.

A biblioteca é automatizada com o software PHL, o que facilita a organização e a pesquisa feita pelos usuários. Outras vantagens que valem destaque é o trabalho de curadoria do conteúdo online, que disponibiliza materiais com fontes confiáveis sobre diversos assuntos, inclusive aqueles ligados à pandemia da COVID-19, e a o acesso remoto às coleções digitais, permitindo o andamento de pesquisas científicas e um melhor acompanhamento de aulas a distância.

\section{Uma aliada no acesso à cultura e à educação}

Conforme a Digital Library Federation (DLF), "as bibliotecas digitais são organizações que proporcionam os recursos, inclusive o pessoal especializado, para selecionar, estruturar, oferecer o acesso intelectual, interpretar, distribuir, preservar a integridade e assegurar a persistência temporal das coleções de trabalhos digitais, de maneira que estejam prontamente e economicamente disponíveis para o uso de uma comunidade definida ou um conjunto de comunidades".

Ou seja, mais do que um compilado de materiais on-line, uma biblioteca digital deve zelar pela qualidade e confiabilidade dos itens disponíveis em seu acervo, bem como garantir sua manutenção, atualização e formas de acesso.

Para Fernanda Costa, elas não são apenas uma versão on-line de uma biblioteca física, mas sim aliadas no compromisso de universalizar o acesso à cultura, arte e educação. "Neste momento, seu principal objetivo é permitir o avanço de pesquisas e dar apoio aos estudantes que continuam tendo aulas durante a pandemia, além de disponibilizar obras literárias, difundindo a cultura e incentivando a leitura como parceira durante esta fase crítica que vivemos", conclui.

\section{Conheça a Biblioteca Digital da Faculdade Unimed}

Para fazer uma pesquisa, acesse faculdadeunimed.edu.br/biblioteca. Procure por assunto, autor ou título. Apenas os materiais on-line estão disponíveis para download e estão identificados com o símbolo "Sítio Web". 